\title{
Declining soil-root hydraulic conductance drives stomatal closure of tomato under drought
}

\section{Other Conference Item}

\section{Author(s):}

Abdalla, Mohanned; Carminati, Andrea (D); Cai, Gaochao; Javaux, Mathieu; Ahmed, Mutez

Publication date:

2021-04

\section{Permanent link:}

https://doi.org/10.3929/ethz-b-000527182

Rights / license:

Creative Commons Attribution 4.0 International

Originally published in:

EGUsphere, https://doi.org/10.5194/egusphere-egu21-4192 


\title{
EGU21-4192
}

https://doi.org/10.5194/egusphere-egu21-4192

EGU General Assembly 2021

(c) Author(s) 2022. This work is distributed under

the Creative Commons Attribution 4.0 License.

\section{Declining soil-root hydraulic conductance drives stomatal closure of tomato under drought}

\author{
Mohanned Abdalla ${ }^{1,2}$, Andrea Carminati ${ }^{3}$, Gaochao Cai ${ }^{1,4}$, Mathieu Javaux ${ }^{5,6}$, and Mutez Ahmed ${ }^{1,4}$ \\ ${ }^{1}$ Chair of Soil Physics, Bayreuth Center of Ecology and Environmental Research (BayCEER), University of Bayreuth, \\ Universitätsstraße 30, 95447, Bayreuth, Germany. \\ ${ }^{2}$ Department of Horticulture, Faculty of Agriculture, University of Khartoum, Khartoum North 13314 Shambat, Sudan. \\ ${ }^{3}$ Physics of Soils and Terrestrial Ecosystems, Institute of Terrestrial Ecosystems, Department of Environmental Systems \\ Science, ETH Zürich, Universitätstr. 16, 8092, Zurich, Switzerland. \\ ${ }^{4}$ Biogeochemistry of Agroecosystems, University of Göttingen, Göttingen, Germany. \\ ${ }^{5}$ Earth and Life Institute-Environmental Science, Universite Catholique de Louvain, Louvain la Neuve, Belgium. \\ ${ }^{6}$ Agrosphere (IBG-3), Forschungszentrum Juelich GmbH, Juelich, Germany.
}

The fundamental question as to what triggers stomatal closure during soil drying remains contentious. Thus, we urgently need to improve our understanding of stomatal response to water deficits in soil and atmosphere. Here, we investigated the role of soil-plant hydraulic conductance $\left(\mathrm{K}_{\mathrm{sp}}\right)$ on transpiration $(\mathrm{E})$ and stomata regulation. We used a root pressure chamber to measure the relation between $\mathrm{E}$, leaf xylem water potential $\left(\psi_{\text {leaf- }}\right)$ and soil water potential $\left(\psi_{\text {soil }}\right)$ in tomato. Additional measurements of $\psi_{\text {leaf-x }}$ were performed with unpressurized plants. A soil-plant hydraulic model was used to simulate $E\left(\psi_{\text {leaf- } x}\right)$ for decreasing $\psi_{\text {soil }}$. In wet soils, $E\left(\psi_{\text {leaf- } x}\right)$ had a constant slope while in dry soils the slope decreased, with $\psi_{\text {leaf-x }}$ rapidly and nonlinearly decreasing for moderate increases in E. The $\psi_{\text {leaf-x }}$ measured in pressurized and unpressurized plants matched well, which indicates that the shoot hydraulic conductance did not decrease during soil drying and that the decrease in $\mathrm{K}_{\mathrm{sp}}$ is caused by a decrease in soil-root conductance. The decrease of $E$ matched well the onset of hydraulic nonlinearity. Our findings demonstrate that stomatal closure prevents the drop in $\psi_{\text {leaf-x }}$ caused by a decrease in $\mathrm{K}_{\mathrm{sp}}$ and elucidate a strong correlation between stomatal regulation and belowground hydraulic limitation. 